\title{
Ndrg2 promoter hypermethylation triggered by helicobacter pylori infection correlates with poor patients survival in human gastric carcinoma
}

\author{
Zhi-Qiang Ling ${ }^{1}$, Ming-Hua Ge ${ }^{2}$, Xiao-Xiao Lu ${ }^{1}$, Jin Han ${ }^{1}$, Yi-Chen Wu ${ }^{1}$, Xiang Liu ${ }^{1}$, \\ Xin Zhu ${ }^{1}$ and Lian-Lian Hong ${ }^{1}$ \\ ${ }^{1}$ Zhejiang Cancer Research Institute, Zhejiang Province Cancer Hospital, Zhejiang Cancer Center, Hangzhou, China \\ 2 Department of Tumor Surgery, Zhejiang Province Cancer Hospital, Zhejiang Cancer Center, Hangzhou, China \\ Correspondence to: Zhi-Qiang Ling, email: lingzq@zjcc.org.cn or lingzq@hotmail.com \\ Keywords: gastric carcinoma, Helicobacter pylori (H. pylori) infection, DNMT3b, N-myc downstream regulated gene 2 (Ndrg2), \\ promoter methylation \\ Received: September 20,2014 Accepted: February 03, $2015 \quad$ Published: March 15, 2015
}

This is an open-access article distributed under the terms of the Creative Commons Attribution License, which permits unrestricted use, distribution, and reproduction in any medium, provided the original author and source are credited.

\section{ABSTRACT}

$\mathrm{N}$-myc downstream regulated gene $\mathbf{2}(\mathrm{Ndrg} 2)$ is a candidate suppressor of cancer metastasis. We found that $\mathbf{N d r g} 2$ promoter was frequently hypermethylated in gastric cancer cell lines and in $\mathbf{2 9 2}$ gastric tumor tissues. This resulted in down-regulation of Ndrg 2 mRNA and protein. Ndrg2 promoter methylation was associated with H. pylori infection and worse prognosis of gastric cancer patients, which is an independent prognostic factor for the disease-free survival (DFS). We found that $\mathrm{H}$. pylori silenced Ndrg2 by activating the NF-KB pathway and up-regulating DNMT3b, promoting gastric cancer progression. These findings uncover a previously unrecognized role for $\mathbf{H}$. pylori infection in gastric cancer.

\section{INTRODUCTION}

Gastric cancer (GC) is one of the most deadly diseases worldwide, mainly attributing to the high frequency of metastasis [1]. Being predominantly found in older patients with a long period of atrophic gastritis, GC is thought to result from a combination of environmental factors and the accumulation of genetic alterations [24]. The commonest cause of gastritis is the infection of $H$. pylori, which is the single most common risk factor of gastric cancer [5,6]. $H$. pylori has been classified as a class I carcinogen by the WHO since $1994[7,8]$ and its causal role in $\mathrm{GC}$ has been extensively studied in animal models [9]. However, the role of $H$. pylori infection in the tumorigenesis and tumor progression of gastric cancer is largely elusive.

Human N-Myc downstream-regulated gene ( $\mathrm{Ndrg}$ ) family consists of $N d r g 1, N d r g 2, N d r g 3$, and $N d r g 4$ which locate on chromosomes 8q24.3, 14q11.2, 20q11.2111.23, and 16q21-q22.1, respectively [10]. Functions of Ndrg family have been associated with cell proliferation, differentiation, apoptosis, stress responses, and cell migration/metastasis [11-13]. Down-regulation of Ndrgl and $N d r g 2$ have been reported in various cancer tissues, and have been regarded as tumor suppressors and/or metastasis suppressors $[14,15]$. Ndrg2 contains a CpG island in its promoter region and DNA hypermethylation has been reported in pancreatic cancer [16], glioblastoma $[17,18]$, adrenocortical carcinomas [19], breast cancer $[20,21]$, colorectal cancer $[22,23]$, oral squamous-cell carcinoma [24], meningioma [25], liver [26], and gastric cancer $[27,28]$. The methylation of Ndrg2 was found in $54.0 \%(47 / 87)$ of primary gastric cancer specimens and related to gastric cancer progression [27]. However, till now, nothing has been reported about the relationship between Ndrg2 methylation and $H$. pylori infection in gastric mucosa epithelial cells.

In this study, we investigated the expression level and methylation status of Ndrg2 in 292 gastric cancer and matched noncancerous tissues, and we evaluated the clinical significance of abnormal $\mathrm{Ndrg} 2$ methylation in gastric cancer. We also evaluated the correlation between $N d r g 2$ methylation and $H$. pylori infection in gastric cancer. Finally, we explored the possible mechanism of $H$. pylori infection in mediating Ndrg2 promoter methylation in vitro. Our results suggested that $H$. pylori may function as an initiator in the progression of gastric cancer by regulating DNA methyltransferase $3 b$ (DNMT3b). 


\section{RESULTS}

\section{Ndrg2 is significantly down-regulated in human gastric cancer cells and primary gastric cancer tissues}

To investigate the candidacy of $\mathrm{Ndrg} 2$ as a suppressor in gastric progression, we initially characterized the expression status of $\mathrm{Ndrg} 2$ transcript in five gastric cancer cell lines. $N d r g 2$ mRNA expression is significant lower in 4 of 5 gastric cancer cell lines as compared to the average level of 40 normal gastric mucosas from healthy individuals examined (Figure 1
A1-A2); almost undetectable in HGC-27 cells and relative higher in SGC-7901 cells (Figure 1 A1-A2). Western blotting analysis validated the mRNA expression results, confirming that the Ndrg2 protein levels in the 4 cell lines are non-detectable (Figure 1 A3).

Next, we evaluated $N d r g 2$ mRNA expression level in 292 primary gastric cancer tissues, as well as their corresponding para-cancerous histological normal tissue (PCHNT) specimens and 125 non-cancer volunteers. mRNA expression level (Ndrg2/Gapdh) in GCs $(0.135$ 2.062 , mean $=0.749$ ) is markedly reduced as compared to PCHNTs $(0.248-1.972$; mean $=1.367, P<0.05)$, dysplasia (0.772-2.004; mean=1.755, $P<0.05)$, chronic nonatrophic gastritis $(0.786-2.042$; mean $=1.685, P<0.05)$, and healthy individuals (1.266-2.041; mean $=1.59, P<0.05)$,

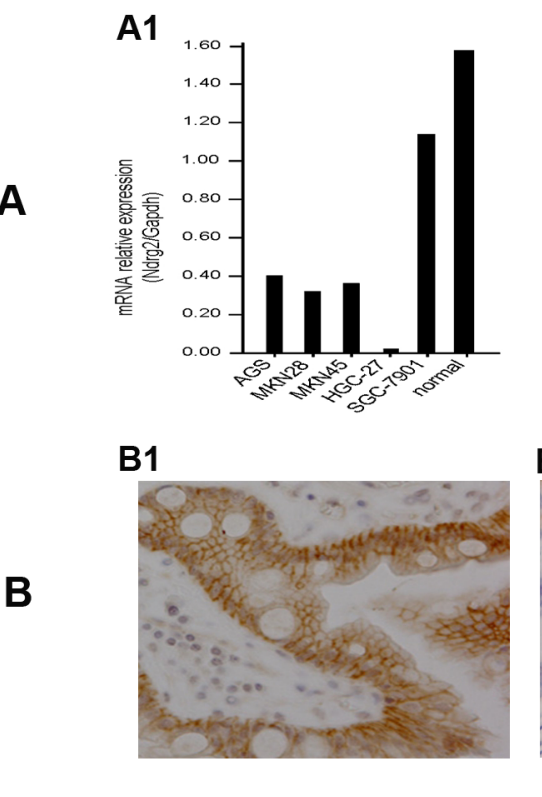

A2

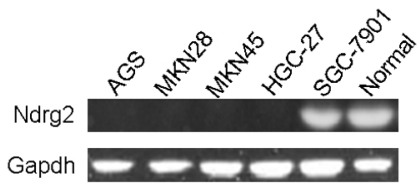

B2

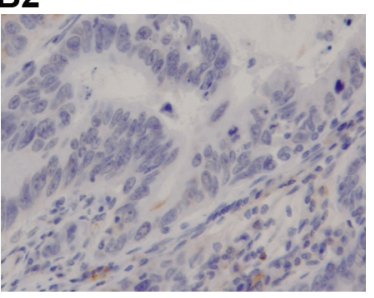

A3

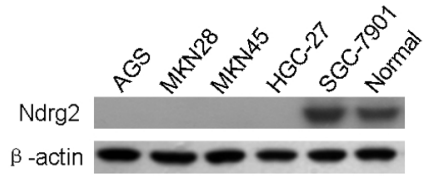

B3
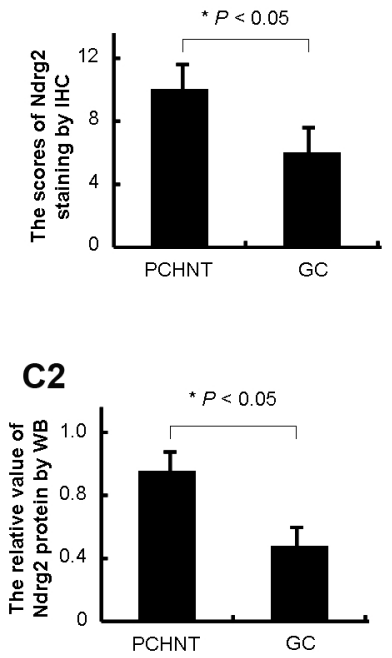

Figure 1: Expression of Ndrg2 is significantly reduced in gastric cancer cells. The relative level of $N d r g 2$ transcript in gastric cancer cell lines in comparison with normal gastric mucosa epithelial tissues from patients undergoing gastroscope examination is shown in A1. Ndrg2 mRNA level was determined by RT-PCR and adjusted for Gapdh. The tumor/PCHNT ratio $<0.5$ is considered as low expression and $>2$ to be considered as high expression. The mRNA level of Ndrg2 in gastric cancer cell lines as determined by $2.0 \%$ agarose gel electrophoresis is shown in A2. The protein level of Ndrg2 in gastric cancer cell lines as determined by western blot (WB) is shown in A3. $\beta$-actin was internal reference. The Ndrg2 protein results by western blot compared with the Ndrg2 mRNA results by RT-PCR have the better consistency. Representative immunohistochemical (IHC) images of Ndrg2 expression are shown for normal gastric tissues (B1) and cancer tissues (B2). $\times 200$ for all images. The protein level of Ndrg2 in 292 primary gastric cancer tissues as determined by IHC is shown in B3. IHC score of 0-4 is considered to be no to low expression and 5-12 considered to be normal to high expression. The level of Ndrg2 expression in PCHNTs is higher than that in tumor tissues $(P<0.05)$. The protein level of Ndrg2 in thirty specimens of gastric cancer and paired normal gastric epithelium tissues as determined by WB is shown in C. Representative WB images of Ndrg2 expression are shown in $\mathrm{C} 1$, and in comparison with IHC results. $\beta$-actin was internal control. Western blot analysis of Ndrg2 protein showed that the differences between tumor and PCHNT groups were significant $(P<0.05)(\mathrm{C} 2)$. 
Table 1: Correlation between $N d r g 2$ mRNA, Ndrg2 protein, $N d r g 2$ methylation and clinicopathologic parameters, respectively

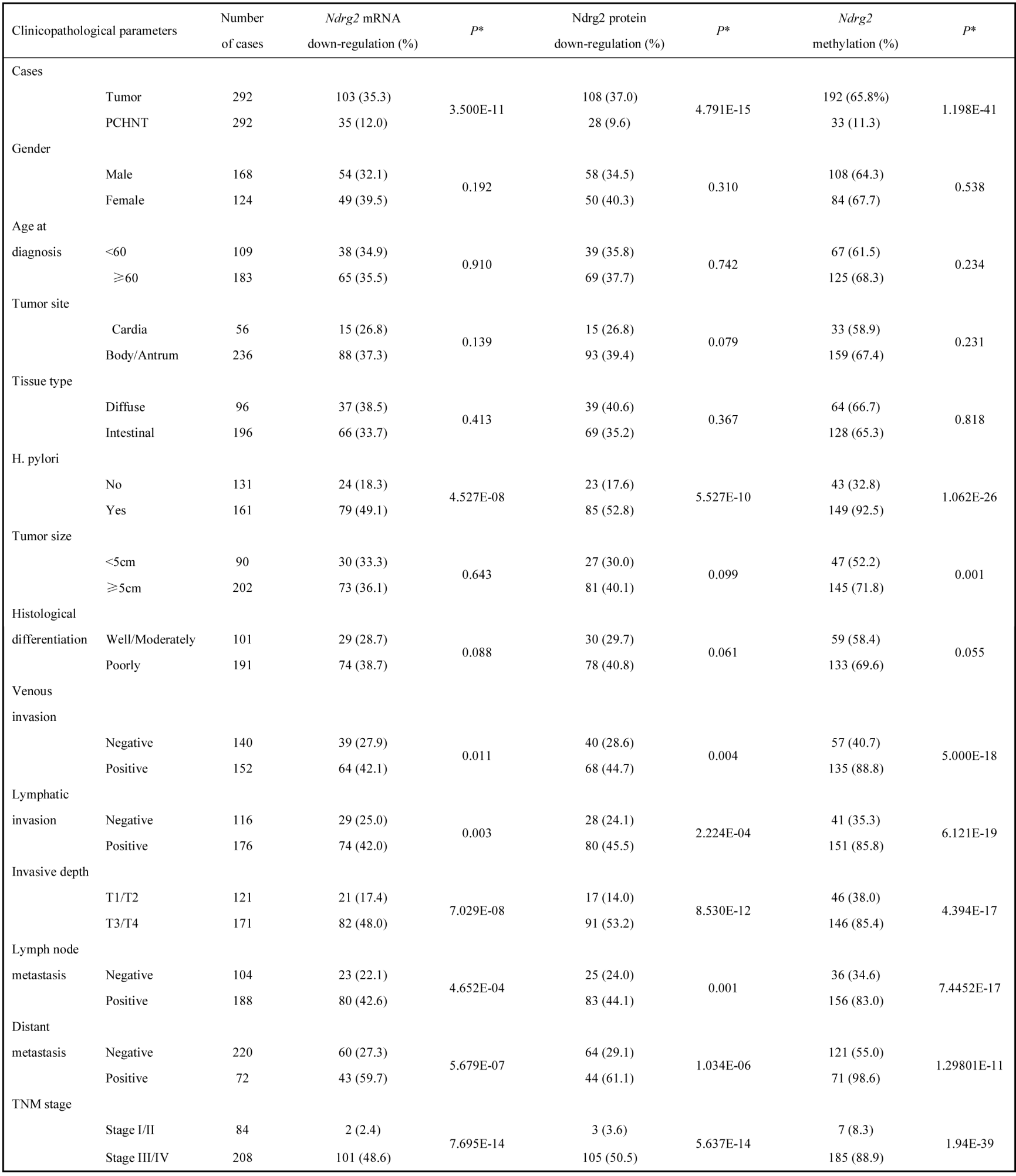

Down: $\mathrm{T} / \mathrm{N}<0.5$ in mRNA, IHC score $\leqslant 4$.

M: methylated score $\geqslant 1$.

$P$ : Pearson Chi-Square Tests. 
respectively (Supplementary Figure 1). There was no significant difference in $\mathrm{Ndrg} 2$ expression in PCHNTs or in dysplasia as compared to other non-cancer controls (all $P>0.05$ ).

To confirm the above mRNA results, we subsequently analyzed $\mathrm{Ndrg} 2$ protein expression in 292 GCs and their corresponding PCHNTs using immunohistochemical (IHC) assay. Ndrg2 protein was expressed in the cytoplasm and plasma membrane in histological normal gastric epithelial cells (PCHNTs) with a moderate to strong staining intensity (Figure 1 B1). However, gastric cancer tumor cells displayed significantly reduced Nrdg2 protein expression as compared to PCHNT (Figure 1 B2-B3). We also carried out western blot analyses to confirm the above IHC findings in 30 randomly selected matched primary PCHNT and tumor tissue samples. Some representative western blot results are shown in Figure $1 \mathrm{C} 1$. The average bands intensity of Ndrg2 in gastric cancer is significantly lower than that in PCHNT $(P<0.05$, Figure $1 \mathrm{C} 2)$. The protein levels of Ndrg2 determined by IHC in the 292 GC samples correlated well with the mRNA level of Ndrg2 detected by real-time RT-PCR ( $\mathrm{r}=0.714, P=0.000)$ (Figure 3$)$. We also analyzed the correlation between Ndrg2 IHC results with clinicopathological factors. The data shows that loss of Ndrg2 protein significantly correlated with $H$. pylori (HP) infection $(P=0.000)$, venous invasion $(P=0.011)$, lymphatic involvement $(P=0.003)$, invasive depth $(P=0.000)$, lymph node metastasis $(P=0.000)$, distant

Figure 2: The analysis of aberrant DNA hypermethylation at the CpG sites in the Ndrg2 promoter. The methylated level of $\mathrm{Ndrg} 2$ in cell lines, primary gastric cancer tissues and paired PCHNTs after real-time MSP analysis as determined by $2.0 \%$ agarose gel electrophoresis is shown in A and B. C: Summary of Ndrg2 methylation in 292 gastric cancers tissues, 292 para-cancerous histological normal tissues (PCHNTs) from the same patients and 88 non-cancer volunteers. Data shows the frequency of Ndrg2 methylation (DNA methylation level $\geq 20 \%$ ) in each group. D: 5-Aza-CdR or/and TSA treatments restored $N d r g 2$ gene expression in $N d r g 2$ silenced HGC-27 cells. Two gastric cancer cell lines (HGC-27 and SGC-7901) were treated with $1.0 \mu \mathrm{mol} / \mathrm{L} 5$-Aza-CdR for 72 hours and/or $100 \mathrm{nM}$ TSA for 24 hours. The methylated levels were determined by real-time MSP. We performed real-time RT-PCR analysis in triplicate for each cDNA sample and used median values in three experiments. The relative $\mathrm{Ndrg} 2 \mathrm{mRNA}$ expression was normolized to the Gapdh of the same samples using the formula $2^{-\triangle \Delta C T}$. The results were multiplied by 100 for a better visualization. The percentage of Ndrg2 DNA methylation is shown on the left side; whereas the relative mRNA expression of $N d r g 2$ is shown on the right side. E: Expression of Ndrg2 at the protein level following 5-Aza-CdR and TSA treatments. Western blot analysis of HGC-27 cells following treatment with DMSO (control), 5-Aza-CdR, or 5-Aza-CdR/TSA for 72 hours demonstrate up-regulation of the Ndrg2 proteins in treated cells as compared to control (DMSO). $\beta$-actin is shown as a loading control.

metastasis $(P=0.000)$ and clinical stage $(P=0.000)$ (Table 1). Collectively, these data indicate that the expression of $\mathrm{Ndrg} 2$ is significantly reduced at mRNA and protein levels in $\mathrm{GC}$ cells, and loss of $\mathrm{Ndrg} 2$ expression may associate with tumor progression and metastasis.

\section{Frequent DNA hypermethylation at the CpG sites in the $N d r g 2$ promoter}

RT-PCR analysis showed that Ndrg2 mRNA expression is repressed in 4 of 5 gastric cancer cell lines examined and in human gastric cancer samples. To understand the molecular mechanism of the predominant transcriptional repression of $N d r g 2$ in gastric cancer cells, we investigated the DNA methylation status of a $\mathrm{CpG}$ island encompassing the proximal promoter of $\mathrm{Ndrg} 2$ using a real-time methylation-specific PCR (MSP). Ndrg2 promoter hypermethylation were detected in HGC-27, AGS, MKN-45 and MKN-28 cell lines in which Nrdg2 are silenced, but was not detected in SGC-7901 (Figure 2A). These results indicate that the transcriptional repression of Ndrg2 in gastric cancer cells is highly correlated with promoter hypermethylation.

To confirm these results, we investigated the DNA methylation status in 292 paired tumor and PCHNT tissues

A

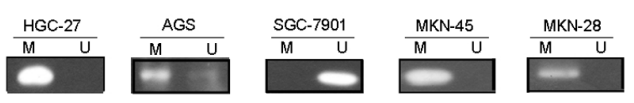

B
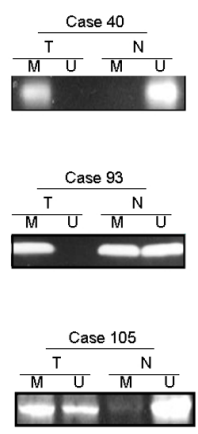

D

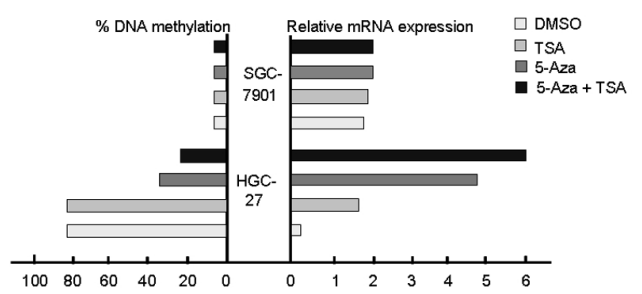

E

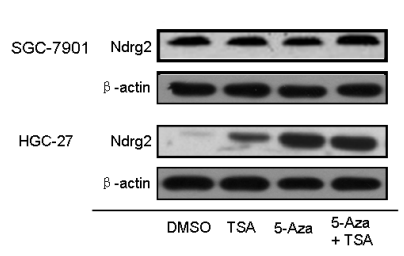

C

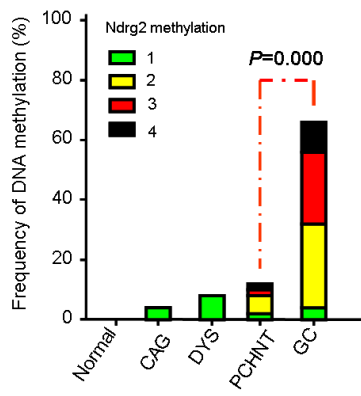


by real-time MSP. The Ndrg2 promoter were frequently hypermethylated in tumor tissues in contrast to the PCHNT tissues of the same individual. Some methyl $\mathrm{CpG}$ sites were also detected in PCHNT tissues but the frequency was much lower than that in tumor tissues (Figure 2B-C). According to our definition, we took $20 \%$ of methylation level as the threshold for DNA hypermethylation. Based on this criterion, the $N d r g 2$ hypermethylation was detected in $65.8 \%(192 / 292)$ of GC tissues and $11.3 \%(33 / 292)$ of PCHNTs, respectively $(P=0.000)$. The latter were found to be mostly partially methylation of $N d r g 2$ gene, which methylation score less than 4. While the methylated frequency of Ndrg2 in non-cancer controls were $4.0 \%$ $(5 / 125)$. The frequency of $N d r g 2$ methylation in GC tissues and PCHNTs was significant higher than that in non-cancer control ( $P=0.000$, and $P<0.05$, respectively) (Figure 2C).

\section{Promoter methylation of $\mathrm{Ndrg} 2$ gene was correlated with its down-regulation at both mRNA and protein levels}

To examine the relationship between Ndrg2 methylation and $N d r g 2$ expression, we compared the Ndrg 2 methylation level with $N d r g 2$ mRNA or protein level determined by IHC using the Spearman correlation analysis. As shown in Figure 3, Ndrg2 methylation significantly correlated with $N d r g 2$ mRNA level ( $\mathrm{r}=-0.658$, $P=0.000)$ and $N d r g 2$ protein level $(\mathrm{r}=-0.872, P=0.000)$. And $N d r g 2$ protein expression (determined by IHC analysis) in 292 GC tissues was closely correlated with Ndrg 2 mRNA level $[\lg (\mathrm{T} / \mathrm{N})]$ (determined by RT-PCR) $(\mathrm{r}=0.714, P=0.000)$. To further confirm these results, two gastric cell lines (HGC-27 and SGC-7901) were treated with the de-methylating agent 5-aza-2'-deoxycytidine
(5-Aza-CdR). As shown in Figure 2D, Ngrg2 mRNA expression was reactivated in $\mathrm{HGC}-27$ cells with significant demethylation of $N d r g 2$ promoter by 5-Aza$\mathrm{CdR}$, indicating that $\mathrm{Ndrg} 2$ is transcriptionally silenced in these cells by DNA hypermethylation. Interestingly, TSA treatment alone was effective in restoring the expression of Ndrg2 gene in HGC-27 cells, but did not change the methylation levels, suggesting that histone modifications may also be involved in regulating the expression of Ndrg2. However, administration of TSA following 5-Aza$\mathrm{CdR}$ had an additive effect in restoring gene expression and led to a further decrease in the methylation level of Ndrg2 (Figure 2D). These results are in agreement with recent studies that suggested that TSA can have a demethylation effect in a gene-specific manner [29]. The western blot analysis using HGC-27 cell line as a model, confirmed the up-regulation of Ndrg2 proteins following the 5-Aza-CdR and 5-Aza/TSA treatments (Figure 2E). 5-Aza-CdR or TSA treatment alone or 5-Aza/TSA treatments did not have effect on the gene expression of $N d r g 2$ at both mRNA and protein levels in SGC-7901 cells, in which the Ndrg2 promoter was nonhypermethylated (Figure 2D-E). These findings indicate that promoter hypermethylation of $\mathrm{Ndrg} 2$ is the major mechanism for silencing $N d r g 2$ expression in GC.

Of note, the methylated status of $N d r g 2$ significantly correlated with some clinicopathological parameters in GC: H. pylori (HP) infection $(P=0.000)$, tumor size $(P=0.001)$, venous invasion $(P=0.000)$, lymphatic involvement $(P=0.000)$, invasive depth $(P=0.000)$, lymph node metastasis $(P=0.000)$, distant metastasis $(P=0.000)$ and clinical stage $(P=0.000)$. However, there was no significant correlation between the methylated status of Ndrg2 and gender, age at diagnosis, tumor site, histology and differentiation (Table 1).

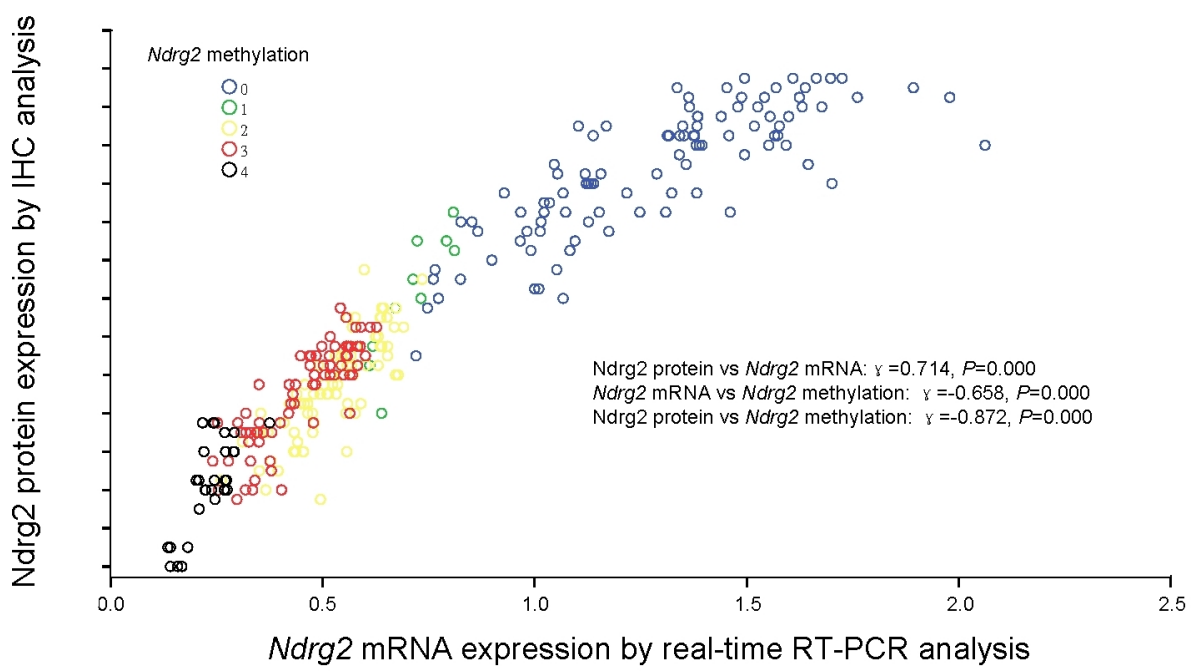

Figure 3: Correlation of $\mathbf{N d r g} 2$ methylation with Ndrg2 expression. Correlation of $N d r g 2$ methylation with $N d r g 2 \mathrm{mRNA}$ level determined by real-time RT-PCR analysis and Ndrg2 protein expression determined by immunohistochemical analysis in 292 gastric cancer tissues. Ndrg2 methylation scores inversely correlated with $\mathrm{Ndrg} 2$ gene expression in both mRNA and protein levels. 
Table 2: Univariate and multivariate analysis of survival in 292 patients with gastric cancer according to clinicopathologic factors and $\mathrm{Ndrg} 2$ methylation

\begin{tabular}{|c|c|c|c|c|c|c|c|c|c|c|c|c|c|}
\hline \multirow{3}{*}{$\begin{array}{c}\text { Clinicopathologic } \\
\text { factor }\end{array}$} & \multicolumn{7}{|c|}{ DFS } & \multicolumn{6}{|c|}{$\mathrm{OS}$} \\
\hline & \multirow{2}{*}{$\begin{array}{c}\text { Total } \\
\mathrm{n}\end{array}$} & \multirow{2}{*}{$\begin{array}{c}\text { Survival } \\
(\mathrm{mo})\end{array}$} & \multicolumn{2}{|c|}{ Univariate analysis } & \multicolumn{3}{|c|}{ Multivariate analysis ${ }^{\S}$} & \multirow{2}{*}{$\begin{array}{c}\text { Survival } \\
\text { (mo) }\end{array}$} & \multicolumn{2}{|c|}{ Univariate analysis } & \multicolumn{3}{|c|}{ Multivariate analysis ${ }^{\S}$} \\
\hline & & & $\chi^{2}$ & P-values & HR & $(95 \% \mathrm{CI})$ & $\mathrm{P}$ & & $\chi^{2}$ & P-values & HR & $(95 \% \mathrm{CI})$ & $\mathrm{P}$ \\
\hline \multicolumn{14}{|l|}{ Gender } \\
\hline Male & 168 & 36.1 & \multirow{2}{*}{0.323} & \multirow{2}{*}{0.570} & \multirow{2}{*}{1.510} & \multirow{2}{*}{$1.039-2.196$} & \multirow{2}{*}{0.031} & 52.6 & \multirow{2}{*}{9.082} & \multirow{2}{*}{0.003} & \multirow{2}{*}{1.879} & $1006-3500$ & 0.048 \\
\hline Female & 124 & 35.0 & & & & & & 45.9 & & & & $1.000-5.309$ & 0.040 \\
\hline Age at diagnosis & & & & & & & & & & & & & \\
\hline$<60$ & 109 & 39.5 & 6607 & 0010 & 0048 & $0650-365$ & 0.774 & 53.2 & 0350 & 0000 & 1054 & 0.5132165 & $0.886-2-1$ \\
\hline$\geqslant 60$ & 183 & 33.7 & 0.021 & 0.010 & 0.940 & S0נ. & 0.114 & 47.8 & 9.539 & 0.002 & 1.004 & $0.315-2.105$ & 0.000 \\
\hline Tumor site & & & & & & & & & & & & & \\
\hline Body/Antrum & 56 & 35.8 & 0081 & 0.776 & 0080 & $0.654+473$ & 0020 & 49.4 & 2310 & 0120 & 1771 & $0810=870$ & $0152-15$ \\
\hline Cardia & 236 & 36.8 & 0.001 & 0.170 & 0.902 & $0.054-1.4 / 3$ & 0.929 & 52.4 & 2.310 & 0.129 & 1.171 & $0.010-5.070$ & $0.152+2$ \\
\hline Tissue type & & & & & & & & & & & & & \\
\hline Diffuse & 96 & 37.3 & 1720 & 0100 & 1086 & 07571560 & 0654 & 50.9 & 3585 & 0058 & 1260 & 06642308 & 04777 \\
\hline Intestinal & 196 & 34.9 & 1.120 & 0.190 & 1.000 & $0.157-1.500$ & 0.054 & 49.0 & 3.585 & 0.058 & 1.202 & $0.004-2.390$ & $0.4 / 1$ \\
\hline H. pylori & & & & & & & & & & & & & \\
\hline Negative & 131 & 48.7 & $148 \quad 156$ & $4285 \mathrm{~F}_{3}$ & 2612 & $1540+4400$ & $3185 \mathrm{~F} 04$ & 58.7 & 67648 & 1054 Г 16 & 4605 & 1101.18512 & 0027 \\
\hline Positive & 161 & 24.3 & 148.150 & $4.385 E-34$ & 2.013 & $1.549-4.409$ & $3.185 \mathrm{E}-04$ & 38.5 & $0 / .048$ & $1.954 \mathrm{E}-10$ & 4.095 & $1.191-18.513$ & 0.021 \\
\hline Tumor size & & & & & & & & & & & & & \\
\hline$<5 \mathrm{~cm}$ & 90 & 41.1 & 1101 & 0001 & 1081 & 07271606 & 0700 & 54.7 & 7815 & 0005 & 1260 & 06070618 & 0.525 \\
\hline$\geqslant 5 \mathrm{~cm}$ & 202 & 33.5 & 11.101 & 0.001 & 1.081 & $0.12 /-1.606$ & 0.100 & 47.3 & 1.815 & 0.005 & 1.260 & $0.60 /-2.618$ & 0.535 \\
\hline Differentiation & & & & & & & & & & & & & \\
\hline Poorly & 101 & 34.3 & 4.214 & 0.040 & 0.896 & $0.609-1.318$ & 0.576 & 47.4 & 6.050 & 0.014 & 0.674 & $0.335-1.356$ & 0.269 \\
\hline Well/Medium & 191 & 38.4 & & & & & & 53.8 & & & & & \\
\hline Venous invasion & & & & & & & & & & & & & \\
\hline No & 140 & 46.3 & 05080 & $1160 \Gamma^{2} 27$ & 0014 & 02001664 & 0.572 & 54.6 & & & & & 10 010 \\
\hline Yes & 152 & 25.7 & 95.980 & $1.100 \mathrm{E}-22$ & 0.814 & $0.398-1.664$ & $0.5 / 3$ & 43.3 & 21.126 & $4.301 \mathrm{E}-06$ & $0.5 / 4$ & $0.196-1.682$ & 0.312 \\
\hline Lymphatic invasion & & & & & & & & & & & & & \\
\hline No & 116 & 48.1 & 93.128 & $4003 E_{-}-27$ & 2216 & $1012-4853$ & 0047 & 55.8 & 23.405 & $1312 F_{-06}$ & 1444 & 03875303 & 0585 \\
\hline Yes & 176 & 26.8 & 95.120 & $4.9035-22$ & 2.210 & $1.012-4.030$ & 0.041 & 44.1 & 25.405 & $1.512 \mathrm{E}-00$ & 1.444 & $0.501-5.595$ & 0.003 \\
\hline Invasive depth & & & & & & & & & & & & & \\
\hline $\mathrm{T} 1 / \mathrm{T} 2$ & 121 & 45.4 & 68601 & $1206=16$ & 1615 & & & 55.6 & & & & & \\
\hline $\mathrm{T} 3 / \mathrm{T} 4$ & 171 & 27.2 & 68.601 & $1.206 \mathrm{E}-16$ & 1.615 & $1.082-2.411$ & 0.019 & 43.4 & 23.521 & $1.236 \mathrm{E}-06$ & 1.927 & $0.939-3.955$ & 0.074 \\
\hline Nodal & & & & & & & & & & & & & \\
\hline metastasis & & & & & & & & & & & & & \\
\hline No & 104 & 47.8 & 65004 & $4523 F_{-}-16$ & 25.15 & 15634144 & 1. 721504 & 53.2 & 5580 & 0018 & 1814 & - & 0070 \\
\hline Yes & 188 & 28.5 & 65.994 & $4.523 \mathrm{E}-16$ & 2.545 & $1.563-4.144$ & $1.121 \mathrm{E}-04$ & 46.2 & 5.589 & 0.018 & 1.814 & $0.952-3.453$ & 0.070 \\
\hline Distant metastasis & & & & & & & & & & & & & \\
\hline No & 220 & 41.4 & 256750 & $8760 F_{-}-58$ & 10.90 & $6.689-17.77$ & 9351F-27 & 57.9 & 300243 & $3107 \mathrm{~F}_{6} 60$ & 79.02 & $25.723-242.79$ & 2.339 \\
\hline Yes & 72 & 16.7 & 250.150 & $0.709 \mathrm{~L}^{-50}$ & 3 & 2 & 9.JJ1L-22 & 20.9 & 509.243 & $3.192 \mathrm{E}-09$ & 8 & 7 & E-14 \\
\hline TNM stage & & & & & & & & & & & & & \\
\hline $\mathrm{I} / \mathrm{II}$ & 84 & 54.6 & 140758 & $1817 F_{-}-32$ & 36.06 & $7.849-165.7$ & $4062 F_{2} 06$ & 59.6 & 40712 & 1 764F_10 & 49468 & $1.224 \mathrm{E}-64-2.0$ & 0803 \\
\hline III/IV & 208 & 24.9 & 140.150 & $1.01 / \mathrm{L}-32$ & 4 & 04 & $4.002 \mathrm{~L}-00$ & 34.9 & 40.112 & $1.7045-10$ & .676 & $00 \mathrm{E}-73$ & 0.093 \\
\hline Ndrg2 methylation & & & & & & & & & & & & & \\
\hline $\mathrm{MS}^{*}=0$ & 100 & 53.2 & 154721 & $1.612 \mathrm{E}-3$ & 5700 & $2.774-11.71$ & $2184 \mathrm{~F}-06$ & 59.3 & 47.715 & $4929 \mathrm{~F}-12$ & 3254 & $0.528-20.040$ & 0.203 \\
\hline $\mathrm{MS}=1-4$ & 192 & 24.9 & 134.121 & 5 & 5.100 & 6 & $2.184 \mathrm{E}-00$ & 40.6 & 47.115 & $4.929 \mathrm{E}-12$ & 3.254 & $0.528-20.040$ & 0.203 \\
\hline
\end{tabular}

Ndrg2 methylation is closely associated with the prognosis of the gastric cancer patients

We next investigated the association of $\mathrm{Ndrg} 2$ methylation with patient survival. We analyzed both disease-free survival (DFS) and overall survival (OS). In both situations, Ndrg2 methylation is significantly associated with poorer prognosis; shorter DFS and lower OS. The average durations of DFS and OS in patients with Ndrg2 methylation in the tumors (Methylation score
$=1-4)$ were significantly shorter than those of patients without Ndrg2 methylation in the tumors (Figure 4). The average DFS in patients with $\mathrm{Ndrg} 2$ methylation was 24.9 months vs 53.2 months in patients without $N d r g 2$ methylation. The average OS in patients with $\mathrm{Ndrg} 2$ methylation was 40.6 months vs 59.3 months in patients without $N d r g 2$ methylation (Table 2). Ndrg2 methylation was strongly associated with late stage tumors, but the association of Ndrg2 methylation level with patient survival is independent on the tumor stage (Supplementary Figure 2). In addition to Ndrg2 methylation, we observed 
that a number of other previously characterized clinical parameters were associated with patient survival (Table 2), including age at diagnosis, $H$. pylori infection, tumor size, differentiation, venous invasion, lymphatic invasion, invasive depth, nodal metastasis, distant metastasis, and TNM stage. In summary, these data indicate that in addition to a majority of clinical characteristics that have been shown to affect prognosis of gastric cancer patients, the methylation level of $N d r g 2$ might serve as an independent marker to predict the DFS of the patients.

\section{H. pylori infection enhances DNMT activity and expression in vitro}

After $6 \mathrm{~h}$ of $H$. pylori treatment, incubation of SGC7901 cells led to a rapid and significant increase in total DNMT activity by $29.8 \%$ as compared to the controls. At later points in time, DNMT activity was stably increased by approximately $10 \%$ for $12 \mathrm{~h}, 24 \mathrm{~h}, 48 \mathrm{~h}$ time point, and $5 \%$ for $72 \mathrm{~h}$ time point, respectively, where a total increase of more than 60\% was observed (Figure 5A). No significant differences were detected for DNMT1 or DNMT3a protein levels between SGC-7901 cells with and those without $H$. pylori treatment at every time point (Figure 5B). The average DNMT3b protein level for the SGC-7901 cells with $H$. pylori treated was 1.3 -fold at $6 \mathrm{~h}$ and reached a maximum of 1.8-fold at $48 \mathrm{~h}$, compared to the controls (Figure 5B).

Expression of DNMT1, DNMT3a and DNMT3b were then investigated by quantitative real-time RT-PCR. H. pylori treatment significantly increased mRNA for $D N M T 3 b$ while no changes were observed in DNMT1 and DNMT3a levels (Figure 5C). These findings were corroborated by western blot analysis showing a strong increase of DNMT3b protein in H. pylori treatment cells but not of DNMT1 and DNMT3a (Figure 5D). Here, a transient increase in DNMT3b protein levels was observed after 6 to $72 \mathrm{~h}$ in $H$. pylori treatment cells. The DNMT3b expression at both mRNA and protein levels were rapidly increased by $H$. pylori treatment for only $6 \mathrm{~h}$, and increased continuously until $72 \mathrm{~h}$, however, this trend was tending towards stability.

Figure 4: Correlation of Ndrg2 methylation level with survival of patients with gastric cancer. A: Kaplan-Meier curves of overall disease-free survival (DFS) in patients with gastric cancer treated with primary gastrectomy according to the methylated level of Ndrg2. B: Kaplan-Meier curves of overall survival (OS) in patients with gastric cancer treated with primary gastrectomy according to the methylated level of $\mathrm{Ndrg} 2$.
Effects of $\mathrm{H}$. pylori treatment on $\mathrm{Ndrg} 2$ methylation and its molecular mechanism underlying this regulation in vitro

We next investigated whether the increase of DNMT activity and expression is also reflected on the change of methylated status of Ndrg2 promoter. Real-time MSP was performed for Ndrg2 in SGC-7901 cells treated by $H$. pylori at the given time points. The increase of $\mathrm{Ndrg} 2$ methylation (3.8-fold) and the decrease of Ndrg2 mRNA (4.1-fold) in SGC-7901 cells were observed after H. pylori treatment only $6 \mathrm{~h}$ when compared to the level of untreated controls. Ndrg2 methylation level was increased as much as approximately 7.8-fold, while $N d r g 2$ mRNA expression was decreased as much as approximately 8.5 -fold at $48 \mathrm{~h}$ time point in the treated cells as compared to the controls (Figure 5E, F).

$\mathrm{NF} \kappa \mathrm{B}$ plays a critical role during inflammatory response to $\mathrm{H}$. pylori infection. We next examined the

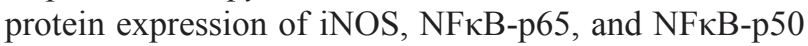
in the SGC-7901 cells. As shown in Figure 6, in $H$. pylori-treated cells, there was a great increase in iNOS,

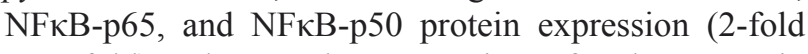
to 5-fold), whereas the expression of Ndrg2 protein was down-regulated (approximately 2-fold to 3-fold),
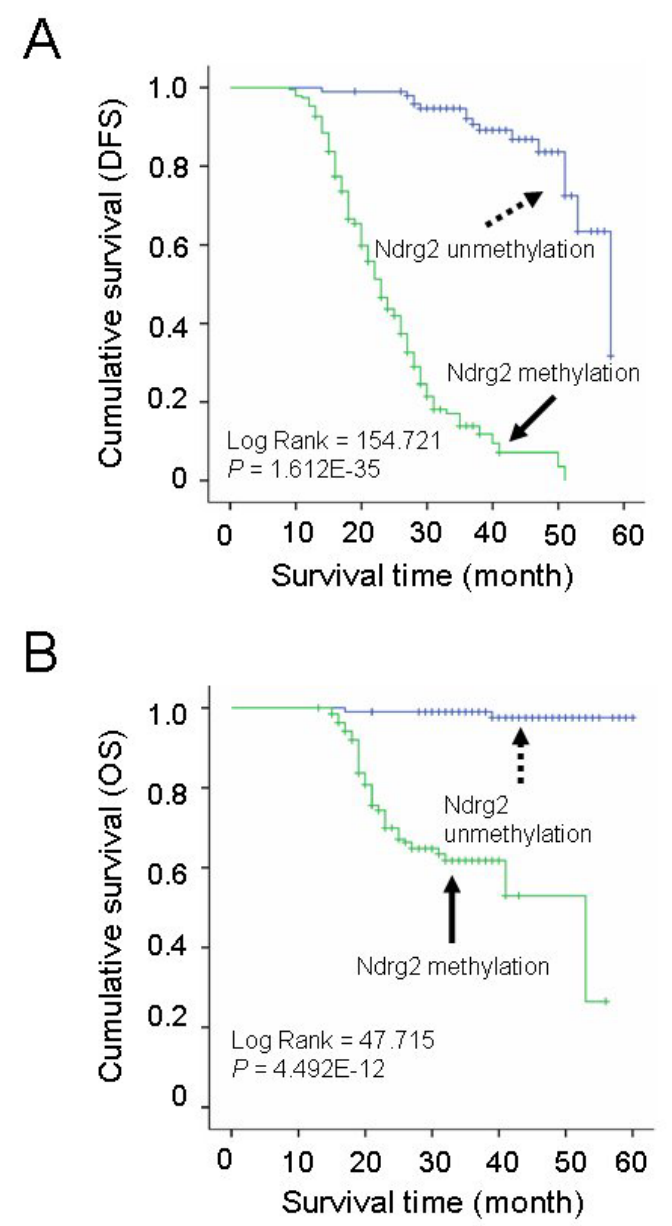
corresponds to the equivalent amount of untreated control cells. Again, when the H. pylori-pretreated cells were cocultured with DNMT3b siRNA, the effects were diminished, and protein expression returned to levels comparable to control cells (Figure 5G). These findings were similar in degree to the mRNA expression analysis of $N d r g 2, i N O S$, $N F \kappa B-p 65$, and $N F \kappa B-p 50$ (data no shown). Promoter methylation of $\mathrm{Ndrg} 2$ was induced in cells SGC7901 treated with $H$. pylori (Figure 5E). No methylation alleles were observed in the control cells without H. pylori challenge. Similarly, the promoter methylation of $\mathrm{Ndrg} 2$ gene disappeared when SGC-7901 cells were pretreated with $H$. pylori and then were cocultured with DNMT3b siRNA (data not shown).

\section{Correlation between DNMT3b expression and $\mathrm{Ndrg} 2$ methylation or $\mathrm{Ndrg} 2$ expression in primary gastric cancer tissues}

To investigates the varied expression of DNA methyltransferase (DNMT) proteins in gastric cancer and their relationship with $N d r g 2$ methylation or $N d r g 2$ expression. Immunohistochemistry was used to detect the expression of the 3 DNMTs in GC tissues. We discovered that the positive rates of DNMT1, DNMT3a, and DNMT3b expression in GC tissues were 78.4\% (229/292), $78.4 \%$ (229/292), and 79.8\% (233/292), respectively, and they were significantly higher than those of three PCHNTs $(19.2 \%, 18.2 \%$, and $14.4 \%)$ and non-cancer control tissues $(8.8 \%, 7.2 \%$, and $6.4 \%)$. DNMT1 was well distributed in the cytoplasm and nuclei of tumor cells or glands, while DNMT3a and 3b were well distributed only in the cytoplasm, as shown by staining a dark brown color. A significant correlation between the DNMT1 and DNMT3a proteins $(P<0.01)$, a low correlation between DNMT3a and DNMT3b $(P=0.06)$, and no correlation between DNMT1 and DNMT3b $(P>0.05)$ were found.

DNMT3b protein level significantly correlated with H. pylori $(\mathrm{HP})$ infection in GC tissues $(P=0.000)$. The frequency of DNMT3b expression in GC tissues with HP infection $(98.8 \%, 159 / 161)$ was significant higher than that those without HP infection $(56 \%, 74 / 131)(P<0.05$, Figure 6A). However, there was no significant correlation between DNMT1 or DNMT3a protein level and HP infection (both $P>0.05$ ). The DNMT1 or DNMT3a protein
A

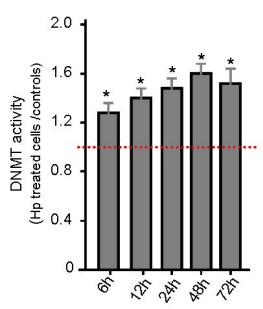

$B$

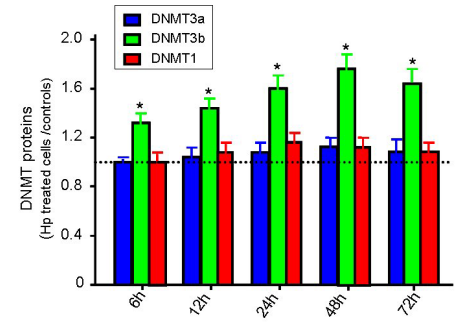

C
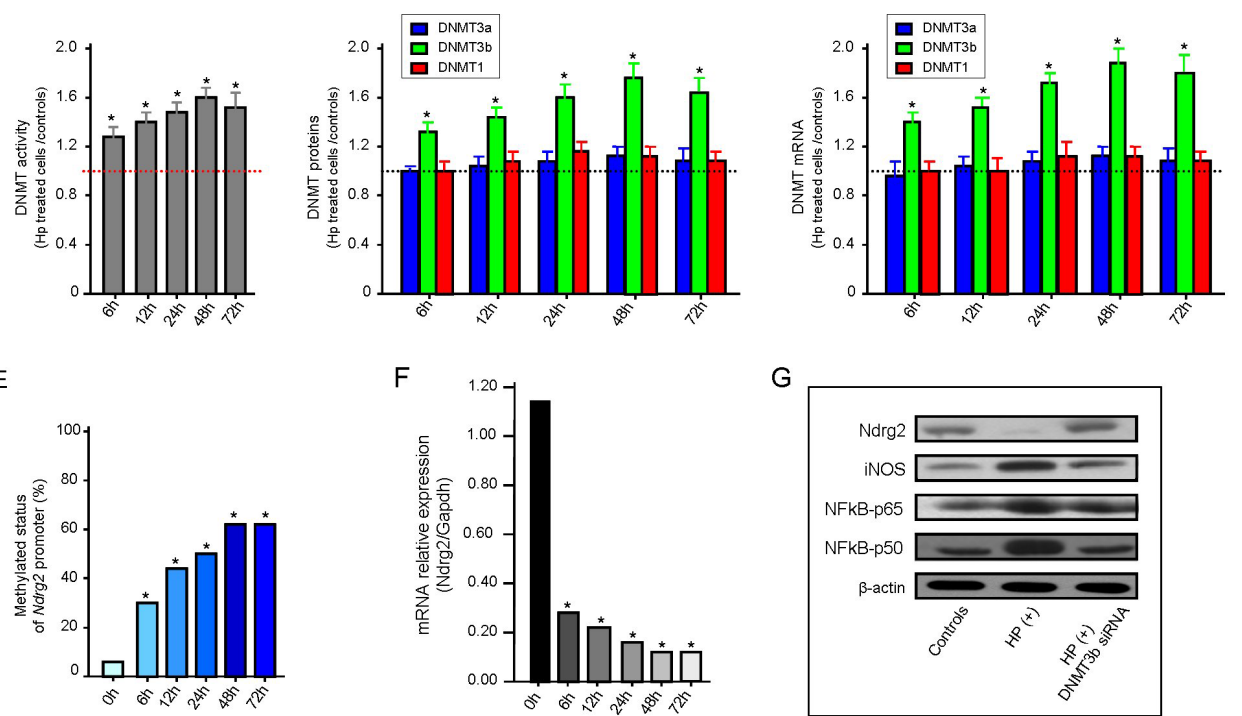

$\mathrm{F}$

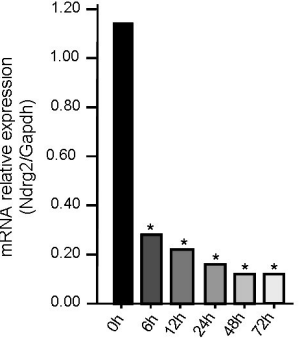

G

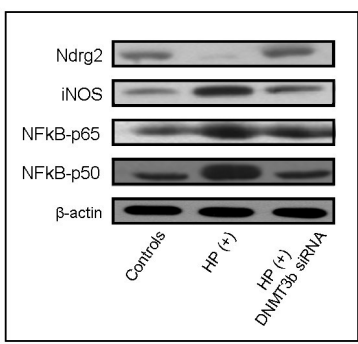

D

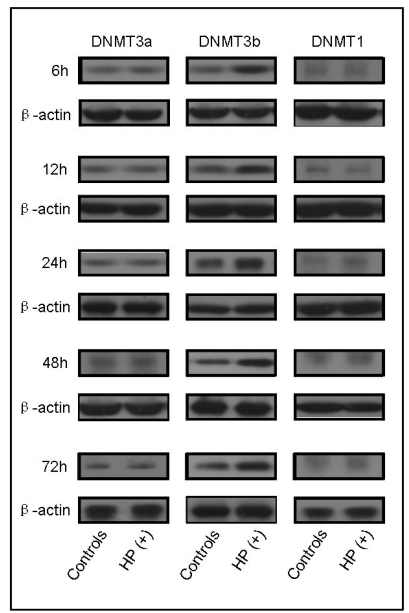

Figure 5: H. pylori infection enhances DNMT activity and NDMT3b expression in vitro. Results from triplicate determination of total DNMT activity and individual DNMT protein assays are shown. Error bars represent S.E.M. A: Fold change of DNMT activity in HP-treated SGC-7901 cells corresponds to the equivalent amount of untreated control cells with a set value of 1.0 for each point in time. * $P<0.05$ vs. untreated controls. B: The total DNMT activity was measured using the EpiQuik ${ }^{\mathrm{TM}}$ DNA Methyltransferase Activity/ Inhibition Assay (Epigentek), and the individual DNMT proteins of interest (DNMT1, DNMT3a, or DNMT3b) was measured using the Epiquik DNMT1, -3a, and -3b assay kits, respectively. Fold change of DNMT protein level in HP-treated SGC-7901 cells corresponds to the equivalent amount of untreated control cells at each point in time using the set value $1.0{ }^{*} P<0.05$ vs. untreated controls. C: Results were normalized to the Gapdh level of each sample and are expressed fold change of DNMT mRNA level in HP-treated SGC-7901 cells corresponds to the equivalent amount of untreated control cells at each point in time using the set value 1.0 . $* P<0.05$ vs. untreated controls. D: Western blot analysis of DNMT expression change in HP-treated SGC-7901 cells. Human $\beta$-actin is used as internal reference. E: Effects of HP infection on Ndrg2 methylation in SGC-7901 cells at each point in time in vitro. $* P<0.05$ vs. untreated controls $(0$ h). F: Effects of HP infection on Ndrg2 mRNA expression in SGC-7901 cells at each point in time in vitro. Ndrg2 mRNA level was determined by RT-PCR and adjusted for Gapdh. ${ }^{*} P<0.05$ vs. untreated controls $(0 \mathrm{~h})$. G: Representative western blots of SGC-7901 cells treated with $H$. pylori or cells pretreated with $H$. pylori and then cocultured with DNTM3b siRNA were shown. Human $\beta$-actin is used as internal reference in each group of western blot analysis. 
in GC tissues with HP infection and those without HP infection were also compared. They coincide well, which the frequency of DNMT3a was 78.3\% (126/161) in HP(+) and $78.6 \%(103 / 131)$ in HP(-) groups, DNMT1 was $78.9 \%$ $(127 / 161)$ in $\mathrm{HP}(+)$ and $77.9 \%(102 / 131)$ in $\mathrm{HP}(-)$ groups (Figure 6A).

The expression of DNMT3b protein in GC tissues significantly correlated with the level of $\mathrm{Ndrg} 2$ methylation $(\mathrm{r}=0.985, P=0.000)$, the level of Ndrg2 mRNA (r=-0.733, $P=0.000)$ and the level of Ndrg2 protein $(\mathrm{r}=-0.660, P=0.000)$, respectively. (Figure 6B, C and D). These findings were consistent with that detected in SGC7901 cells in vitro.

\section{DISCUSSION}

In present study, we investigated the biological function and clinical significance $\mathrm{Ndrg} 2$ in gastric cancer progression. We found that Ndrg2 was frequently down-regulated in gastric cancer and provided evidence suggesting that this observation can have significant implications in the negative regulation of gastric cancer progression. Present studies suggest that Ndrg2 might be a novel candidate suppressor of tumor progression in gastric cancer. First, down-regulation of $N d r g 2$ expression is frequently observed in primary tumors and tumor cell lines. Our data showed that Ndrg2 expression was significantly reduced in the majority of gastric cancers compared with adjacent non-tumor tissues, which is similar to others $[27,28]$. Immunohistochemical analysis of Ndrg2 protein expression in gastric cancer indicated that Ndrg2 expression loss is closely correlated with tumor size, histological differentiation, venous invasion, lymphatic involvement, invasive depth, lymph node metastasis and clinical stage (all $P<0.05$ ) (Table 1). We also found that Ndrg2 down-expression is one of the
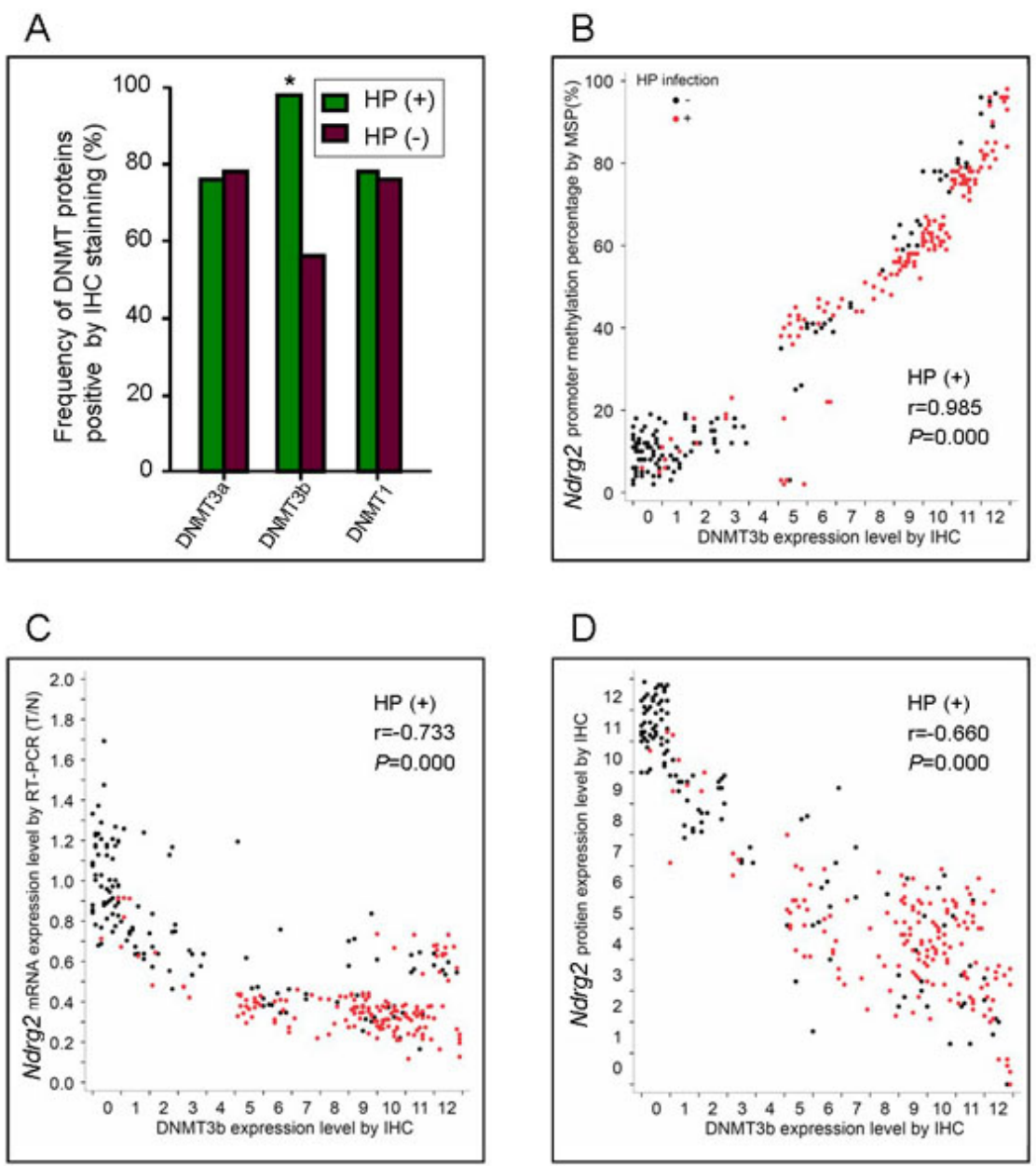

Figure 6: Correlation between DNMT3b expression and Ndrg2 methylation or Ndrg2 expression in primary gastric cancer tissues. A: Comparison of frequency of DNMT proteins expression between in GC with HP infection and those without HP infection, IHS, immunohistochemical score. B: Correlation of DNMT3b protein level with Ndrg2 methylation in GC tissues. C: Correlation of DNMT3b protein level with Ndrg2 mRNA expression in GC tissues. D: Correlation of DNMT3b protein level with Ndrg2 protein expression in GC tissues. 
affecting factors on tumor progression by multivariate analysis. Together, these data indicate that $N d r g 2$ might have a clinical significance as a marker associated with negative regulation of tumor progression in gastric cancer.

The loss of Ndrg2 expression could have been caused by a number of genetic or epigenetic events during gastric cancer progression. In the present study, we showed that the CpG sites in the Ndrg2 promoter were mostly hypermethylated in gastric cancer cell lines and primary tumors, whereas those in normal gastric tissues remained unmethylated. Loss of $\mathrm{Ndrg} 2$ expression due to promoter hypermethylation has been reported in some studies [1728]. We also found that the loss of $N d r g 2$ expression in primary gastric cancer is carried on to the secondary tumors formed during metastatic progression, likely due to inheritance of the promoter hypermethylation pattern at Ndrg2 locus (data no shown). Therefore, we conclude that methylation-induced promoter inactivation might be the major cause of the frequent loss of $\mathrm{Ndrg} 2$ expression in gastric cancer. Using two in vitro cells model of SGC-7901 and HGC-27, we confirmed that DNA methylation is the mechanism underlying $\mathrm{Ndrg} 2$ gene silencing. 5-Aza-CdR treatment significantly restored $\mathrm{Ndrg} 2$ expression in $\mathrm{Ndrg} 2$ silenced gastric cancer cell line HGC-27 cells. These data clearly proved that frequent $\mathrm{Ndrg} 2$ down-expression in gastric cancers is regulated (at least in part) by $\mathrm{Ndrg} 2$ promoter hypermethylation. More importantly, we found that both Ndrg2 hypermethylation and down-regulation of Ndrg2 were significantly correlated with several important clinical parameters such as lymph node metastasis, T-stage, clinical stage, etc (all $P<0.05$ ), suggesting that frequent dysfunction of Ndrg2 through its promoter methylation play crucial roles in malignant progression of human gastric cancer and may have an important impact on the metastasis and poor survival of gastric cancer patients $[27,30]$. Recently, it has been indicated that a lack of $\mathrm{Ndrg} 2$ is associated with oncogenic properties through the loss of its role as a tumor suppressor, and that Ndrg2 is an independent poor prognostic factor predicting survival in clear cell renal cell carcinoma, suggesting that it can serve as a novel prognostic biomarker [31].

Just as important, we found that $\mathrm{Ndrg} 2$ expression loss via DNA methylation is closely correlated with $H$. pylori infection $(P=0.000)$ (Table 1). H. pylori is known to participate in gastric carcinogenesis. Chronic inflammation of the gastric epithelium due to $H$. pylori infection that may lead to an increased risk of gastric cancer [32-34]. In gastric carcinogenesis, aberrant promoter methylation plays a major role by inactivating tumor-suppressor genes. H. pylori may contribute to carcinogenesis through the induction of aberrant methylation in gastric epithelial cells, although further study is necessary to elucidate the detailed molecular mechanisms underlying the induction of aberrant promoter methylation in response to $H$. pylori infection [35-39].

Here, we analyzed $H$. pylori infection and aberrant
Ndrg2 methylation in gastric cancer, the association between $H$. pylori infection and $N d r g 2$ methylation and its possible mechanism. Our results suggest that the mechanism that accounts for $N d r g 2$ methylation in $H$. pylori-related gastric cancer is elevated DNMT activity secondary to the up-regulation of DNMT3b. DNMT3b protein is significantly elevated in HP-related GC tissues and SGC-7901 cells with HP treatment. These SGC-7901 cells treated by HP exhibit aberrantly increased DNMT activity and DNMT3b expression, correspondingly increase of Ndrg2 methylation compared to both those GC tissues and SGC-7901 cells counterparts without HP infection. These results are in agreement with those of other recent studies, in which aberrant DNMT3b upregulation was implicated in the methylation abnormalities of tumors [40-42]. The mechanisms by which H. pylori might promote carcinogenesis are not well understood. H. pylori infection, a major risk factor for gastric cancer, induces the methylation of specific genes in the gastric mucosa [35-39]. Accumulating findings support the idea that the inflammatory response triggered by $H$. pylori infection is responsible for inducing altered DNA methylation [43]. This suggests that $H$. pylori might interact with the $\mathrm{CpG}$ island methylator mechanism of carcinogenesis in response to inflammation. The hypermethylation of $\mathrm{CpG}$ islands, and concomitant loss of gene expression, is the best characterized epigenetic change to occur in tumors and is catalyzed by DNMT1, DNMT3a, and DNMT3b [44, 45]. Classically, DNMT1 is considered a maintenance methyltransferase whereas DNMT3b may be more important for de novo $\mathrm{CpG}$ methylation, although this distinction is not absolute $[46,47]$. DNMT3b up-regulation has been observed in gastric cancer $[48,49]$, but whether $H$. pylori infection during gastric cancer progression have any role in regulating its expression is unclear. Our results suggest that $H$. pylori, as an initiator of the inflammatory tumor microenvironment, might promote the tumorigenesis and progression of gastric cancer through the regulation of epigenetic tumor suppressor genes silencing such as $N d r g 2$ methylation. We also found that $H$. pylori infection induced up-regulation of the DNMT3b but not the DNMT3a and DNMT1 in vitro model.

The potential molecular mechanism underlying the regulation of $\mathrm{Ndrg} 2$ methylation by $H$. pylori infection indicates the role of $H$. pylori in epigenetic modification through an activation of NF- $\mathrm{kB}$ pathway that links inflammation to carcinogenesis. Chronic inflammation is known to promote certain types of cancers, such as gastric cancers. Chronic inflammation and aberrant methylation including promoter and histone methylation are frequently found in $H$. pylori-associated gastric diseases [50, 51]. Liang et al reported that PI3K/AKT-Sp1-RBP2-Cyclin D1 pathway may serve as a novel mechanism for gastric epithelial cell malignant transformation and then gastric cancer (GC) triggered by CagA (+) H. pylori [51]. Hence, 
chronic inflammation caused by $H$. pylori infection is suggested to be an inducer of aberrant methylation $[52,53]$. Our findings were further supported by some recent studies showing that gastric cancer is triggered by $H$. pylori infection in induction of aberrant DNA methylation $[50,52,53]$. However, it is necessary that given a thorough in vivo study using animal models to further characterize the mechanistic role of $\mathrm{NF}-\kappa \mathrm{B}$ pathway in the interaction between H.pylori-induced host inflammatory response and DNA methylation. Even so, we also recognize the diversity and complexity of $H$. pylori-mediated target genes change. The NDRG protein family consists of 4 members, Ndrg1, $N d r g 2, N d r g 3$ and $N d r g 4$, which share $57-65 \%$ amino acid identity [10]. We recently also found that there is different effect of $H$. pylori infection on other members of Ndrg family. Increase of Ndrg 4 promoter methylation triggered by $H$. pylori was found, which is similar to Ndrg2. However, up-regulation of Ndrgl and Ndrg3 was observed when $H$. pylori infection (data no shown). Recently, Bhardwaj et al [54] found that regulation of p53 and E-cadherin is tightly linked through the p53 stress response mechanism that is inhibited by $H$. pylori via activation of Erk1/2-HDM2-p53 pathway leading to survival of damaged cells. Zaika et al [55] suggest that H. pylori has developed clever mechanisms to counteract the function of p53 during the process of evolutionary adaptation to the host environment, and such alteration may increase the risk of tumor development. Zhou et al [56] carried out the study on the molecular mechanism of miRNAs mediated by $H$. pylori in gastric cancer, indicated that miR-203 functions as a growth-suppressive miRNA in H. pylori related GC, and that its suppressive effects are mediated mainly by repressing CASK expression. All these findings reflect the complexity of $H$. pylori infection as the strongest known risk factor for gastric cancer.

In summary, we reported the frequent loss of $\mathrm{Ndrg} 2$ expression in gastric cancer caused by promoter $\mathrm{CpG}$ sites hypermethylation, the significance of the relationship between Ndrg2 expression loss and tumor progression in gastric cancer patients, and the induction of $\mathrm{Ndrg} 2$ methylation by $H$. pylori infection via the activation of $\mathrm{NF} \kappa \mathrm{B}$ pathway and up-regulation of DNMT3b. Our results provided the evidence that $N d r g 2$ could contribute to the negative regulation of gastric cancer progression. Further investigations on the molecular mechanism of Ndrg2 methylation in gastric cancer mediated by H. pylori infection may offer a novel approach for the prevention and treatment of gastric cancer. Understanding these mechanisms could clarify the process of gastric carcinogenesis and progression, and application of this knowledge for clinical use could aid in diagnosis, risk management, prevention and molecular target therapy.

\section{MATERIALS AND METHODS}

\section{Cell lines and $H$. pylori strain}

The human gastric cancer cell lines (AGS, SGC7901, HGC-27, MKN45 and MKN-28) were grown in RPMI-1640 medium (GIBCO, Rockville, MD), supplemented with $10 \%$ fetal bovine serum (FBS), 100 $\mathrm{U} / \mathrm{mL}$ penicillin, and $100 \mathrm{U} / \mathrm{mL}$ streptomycin at $37^{\circ} \mathrm{C}$ and $5 \% \mathrm{CO}_{2}$, respectively. 5-aza-2'-deoxycytidine (5-Aza$\mathrm{CdR}$ ) and trichostatin A (TSA) (Sigma-Aldrich, USA) were dissolved in dimethyl sulfoxide (DMSO). Cultured cells were seeded at a density of $5 \times 10^{5}$ cells per flask. The cells were in logarithmic phase and the number of viable cells was $95 \%$ to $100 \%$ before the addition of 5-Aza$\mathrm{CdR}$ to the culture medium at a final concentration of $1.0 \mu \mathrm{mol} / \mathrm{L}$. The medium was changed daily and the drug concentration was maintained. The cells were collected after $72 \mathrm{~h}$ of drug treatment. Cells were exposed to TSA at a final concentration of $20 \mathrm{ng} / \mathrm{ml}$ for 24 hours. Cells in the untreated group were cultured in normal complete culture medium for $72 \mathrm{~h}$.

H. pylori strain NCTC 11637 was maintained on brain heart infusion agar medium (OXID, Basingstoke, UK) containing $5 \%$ sheep blood incubated at $37^{\circ} \mathrm{C}$ in $5 \%$ $\mathrm{O}^{2}$ for a minimum of two and a maximum of four passages from frozen stocks. $H$. pylori bacteria were added to cultured SGC-7901 cells at ratio of 1:10 and cocultured till total RNA was extracted at 6, 12, 24, 48, and $72 \mathrm{~h}$ after H. pylori induction.

\section{Patients and tissue samples}

A total of 292 patients with gastric cancer, who underwent curative surgery without prior treatments at Zhejiang Province Cancer Hospital from January 2008 to December 2010, were enrolled in this study. Patients with other gastric tumors, such as neuroendocrine tumors, lymphoma, and sarcoma, were excluded from this study. The patients' medical records were reviewed to obtain data including age at diagnosis, sex, tumor location, tumor size (diameter), nerve invasion, and American Joint Committee on Cancer stage. The mean age of patients at tumor resection was 56.1 years; 168 (57.5\%) were male and $124(42.5 \%)$ were female. Demographic, clinical and histopathological parameters of these cases were shown in Table 1. Tumor specimens and corresponding paracancerous histological normal tissues (PCHNTs) were collected at the time of surgery. Paired PCHNTs were obtained from a $5-\mathrm{cm}$ distance from the tumor edge and was assessed microscopically for the presence of normal cells and absence of dysplastic cells. The use of the tissue specimens for the present study obtained patient informed consent, and the use of the human specimens 
was approved by the Zhejiang Province Cancer Hospital Institutional Review Board. As a measure of prognosis, we analyzed the clinical data concerning disease-free survival (DFS) and overall survival (OS), defined as the time from surgery data to first recurrence (DFS), or death (OS) by gastric cancer. All recruited patients had been followedup periodically until the due date. The mean follow-up duration was 28 months, ranging from 11 to 59 months.

Antral mucosa biopsy specimens from 125 noncancer volunteers by gastroscopy were randomly collected as controls within the same period, including 74 men and 51 women, with an average age of 51.8 years old. Among these volunteers, 37 patients were diagnosed with dysplasia (DYS), 48 patients were diagnosed with chronic non-atrophic gastritis (CAG) and 40 healthy individuals without other digestive system diseases. The 125 noncancer volunteers provided written informed consent. Part of the specimens were from Zhejiang Province People's Hospital, the First People's Hospital of ChunAn County and the Center for clinical laboratory of DiAn. The use of the specimen for this study was approved by the Institutional Review Board of Medical Ethics of above institutes.

\section{Real-time RT-PCR analysis}

The mRNA expression of Ndrg2 was analyzed by real-time RT-PCR. Total cellular RNAs were extracted using the Trizol (Gibco) one-step method. A total of $3 \mu \mathrm{g}$ total RNA was subjected to reverse transcription using M-MLV reverse transcriptase (Promega). The glyceraldehyde phosphate dehydrogenase (Gapdh) was selected as the internal reference. Real-time RT-PCR was performed using the following primers: $N d r g 2(\mathrm{~F})-5$ ' -atc tct gga cca get tgc ag-3', Ndrg2 (R)-5'-tat ctc gec agg atg tag gc-3'; Gapdh (F)-5' -ctg ggc tac act gag cac c-3', Gapdh (R)-5' -aag tgg tcg ttg agg gca atg-3'. Primers for DNMT1, DNMT3 $a$ and DNMT3b were purchased from Qiagen. The $2^{-\Delta \Delta C t}$ method was used to calculate relative changes in gene expression determined from real-time RTPCR experiments.

\section{Immunohistochemical analysis}

Immunohistochemistry was performed as described previously [57]. Avidin-biotin-peroxidase method was used for immunohistochemical assay. All sections were deparaffinized with xylene and dehydrated with gradient alcohol followed by inactivation of endogenous peroxidase activity by $0.5 \% \mathrm{H}_{2} \mathrm{O}_{2}$ in methanol for 10 mins. Non-specific binding was blocked by incubation with $10 \%$ normal goat serum in phosphate-buffered saline (PBS) for $1 \mathrm{~h}$ at room temperature. Then, slides were incubated with primary antibodies: anti-Ndrg2 (Abnova, Walnut, CA, USA), and anti-DNMT1/3a/3b
(Santa Cruz Biotechnology, USA), respectively, at $4{ }^{\circ} \mathrm{C}$ overnight, followed by biotinylated goat anti-mouse IgG (1:400; Sigma, St. Louis, MO, USA) or goat antirabbit $\operatorname{IgG}$ (1:400; Sigma) for $1 \mathrm{~h}$ at room temperature. Then streptavidin-biotin-peroxidase- complex assay was performed. A brown color was indicative of protein positive expression. Peroxidase activity was developed by incubating with $0.1 \%$ 3,3-diaminobenzidine (Sigma) in $\mathrm{PBS}$ with $0.05 \% \mathrm{H}_{2} \mathrm{O}_{2}$ for 5 mins at room temperature. The IHC staining score is determined by three independent pathologists based on combining staining frequency and intensity as previous described [50].

\section{Western blot analysis}

Thirty specimens of gastric cancer and their paired normal gastric epithelium tissues from 292 gastric cancer cases were prepared for western blot analysis. Total protein was extracted and then quantified using the Lowry method [58]. Western blot analysis was performed as previous described [57]. $\beta$-actin (TaKaRa Co. Ltd, Kusachi, Japan) was served as an internal control. The bands density was measured by the chemiDoc-XPS Gel imaging system with Epson color image scanner and Image-Pro Plus software and normalized to the $\beta$-actin. The experiments were repeated three times and the mean value was calculated for statistical analysis.

\section{DNA extraction, bisulfite modification and real- time methylation-specific PCR}

Serial 5- $\mu$ m-thick sections that contained carcinoma and non-neoplastic tissues were mounted on non-coated glass slides and dried at $37^{\circ} \mathrm{C}$ overnight. After deparaffinization and staining with Hematoxylin and Eosin (HE), we collected 5000 nuclei from 5 to 10 serial sections using a $27 \mathrm{G}$ needle. The collected target cells were treated with $40 \mu \mathrm{l}$ of $200 \mu \mathrm{g} / \mathrm{ml}$ proteinase $\mathrm{K}$ (Sigma-Aldrich) at $42^{\circ} \mathrm{C}$, for 72 hours. DNAs were modified by sodium bisulfite using the EpiTect Bisulfite kit (Qiagen Inc.) following manufactory's instructions. Modified DNAs were analyzed by real-time methylationspecific PCR (MSP) on a ABI7500 PCR (ABI Co.) using the SYBR Premix Taq ExTaq Kit (TaKaRa Co. Ltd). The specific primers for detection of $\mathrm{Ndrg} 2 \mathrm{CpG}$ island methylation and unmethylation were designed according to previous report [59]. The percentage of methylated DNAs in the samples were calculated according to the $\mathrm{Ct}$ value and a standard curve, and methylated DNA was scored as previous described [39,57]. All samples were analyzed with primer sets for both methylated and unmethylated DNA. The relative amount of methylation in each unknown sample was calculated as the percentage methylation $=100 \times$ (number of copies of methylated DNA / [number of copies of methylated + unmethylated DNA]) 
[60]. The sum of unmethylated plus methylated DNA (U $+\mathrm{M})$ was used as an approximation of the total number of target gene copies. Methylated DNA was scored according to the methylated percentage $(0,<20 \% ; 1,20 \%-40 \% ; 2$, $40 \%-60 \% ; 3,60 \%-80 \%$; and $4,>80 \%$; scores of $0,1-3$, and 4 were considered unmethylated, partially methylated, and fully methylated, respectively) $[39,57,60]$.The cut off threshold for DNA hypermethylation was set as $20 \%$ based on control normal samples and internal quality controls provided in the real-time MSP analysis.

\section{Measurement of DNA methyltransferase (DNMT) activity}

Nuclear protein was isolated with EpiQuik ${ }^{\mathrm{TM}}$ Nuclear Extraction Kit I (Epigentek, Brooklyn, NY, USA) from SGC-7901 cells exposed to H. pylori or from untreated control cells. After protein quantification with Total Protein Kit (Micro Lowry, Peterson's Modification; Sigma-Aldrich Chemie GmbH, Munich, Germany), 12 $\mu \mathrm{g}$ of nuclear protein was used to measure total DNMT activity with the EpiQuik ${ }^{\mathrm{TM}}$ DNA Methyltransferase Activity/Inhibition Assay (Epigentek) in accordance with the manufacturer's instructions. Nuclear extracts were assayed for individual DNMT proteins of interest (DNMT1, DNMT3a, or DNMT3b) using the Epiquik DNMT1, -3a, and -3b assay kits, respectively (Epigentek, Brooklyn, NY, USA), according to manufacturer's protocol.

\section{Knocking down of DNMT3b with RNA interference}

Sequences of RNA interference (RNAi) oligonucleotides were as follows: nonsilencing small interfering RNA (siRNA), UUCUCCGAACGUGUCACGU; DNMT3b siRNA, GATCAAGCTCGCGACTCTC (GeneChem Company, Shanghai, China). Each RNAi oligonucleotide was transfected into cells using the Lipofectamine 2000 transfection kit (Invitrogen, Carlsbad, CA) for $72 \mathrm{~h}$. Cells were harvested and proteins were extracted for western blotting analysis.

\section{Statistical analysis}

SPSS 17.0 statistical software was adopted for data analysis. Counting data comparisons between groups were subjected to the $\chi^{2}$ test or Fisher's exact test. Survival analysis was computed by means of the Kaplan-Meier method and significance were assessed by means of the log-rank test. A univariate analysis of the Cox regression model was used to determine prognostic factors, and multivariate analysis with the Cox regression model was used to explore combined effects. Pearson correlation analysis was used to analyze the correlation between $N d r g 2$ methylation and DNMT1/3a/3b protein. We examined the direct effects of sex, age, tissue type, H. pylori, tissue size, differentiation, $\mathrm{T}$ stage, $\mathrm{N}$ stage, and Ndrg2 methylaion in COX models. For all statistical analyses, $P$ values $<0.05$ were considered to be statistical significance.

\section{ACKNOWLEDGMENTS}

This work was supported by research grants from National Natural Science Foundation of China (81372332), Key Projects from the Natural Science Foundation of Zhejiang Province of China (LZ13H160002), partly sponsored by Zhejiang Provincial Program for the Cultivation of High-level Innovative Health talents (Ling ZQ), and the Major Training Personnel from Zhejiang Provincial Program for the Training and Development Project for 151 talents (Ling ZQ).

\section{DISCLOSURE STATEMENT}

The authors declare no conflict of interest.

\section{REFERENCES}

1. Hu B, El Hajj N, Sittler S, Lammert N, Barnes R, MeloniEhrig A. Gastric cancer: Classification, histology and application of molecular pathology. J Gastrointest Oncol. 2012;3(3):251-261.

2. Milne AN, Sitarz R, Carvalho R, Carneiro F, Offerhaus GJ. Early onset gastric cancer: on the road to unraveling gastric carcinogenesis. Curr Mol Med. 2007;7(1):15-28.

3. Carvalho R, Milne AN, van Rees BP, Caspers E, Cirnes L, Figueiredo C, Offerhaus GJ, Weterman MA. Early-onset gastric carcinomas display molecular characteristics distinct from gastric carcinomas occurring at a later age. J Pathol. 2004;204(1):75-83

4. Resende C, Ristimäki A, Machado JC. Genetic and epigenetic alteration in gastric carcinogenesis. Helicobacter. 2010;15 Suppl 1:34-39.

5. Forman D, Newell DG, Fullerton F, Yarnell JW, Stacey AR, Wald N, Sitas F. Association between infection with Helicobacter pylori and risk of gastric cancer: evidence from a prospective investigation. BMJ. 1991;302(6788):13021305.

6. Parsonnet J, Friedman GD, Vandersteen DP, Chang Y, Vogelman JH, Orentreich N, Sibley RK. Helicobacter pylori infection and the risk of gastric carcinoma. N Engl J Med. 1991;325(16):1127-31.

7. Infection with Helicobacter pylori. IARC Monogr Eval Carcinog Risks Hum. 1994;61:177-240.

8. Suerbaum S, Michetti P. Helicobacter pylori infection. N 
Engl J Med. 2002;347(15):1175-1186.

9. Watanabe T, Tada M, Nagai H, Sasaki S, Nakao M. Helicobacter pylori infection induces gastric cancer in mongolian gerbils. Gastroenterology. 1998;115(3):642648.

10. Zhao W, Tang R, Huang Y, Wang W, Zhou Z, Gu S, Dai J, Ying K, Xie Y, Mao Y. Cloning and expression pattern of the human NDRG3 gene. Biochim Biophys Acta. 2001;1519(1-2):134-138.

11. Shimono A, Okuda T, Kondoh H. N-myc-dependent repression of ndr1, a gene identified by direct subtraction of whole mouse embryo cDNAs between wild type and N-myc mutant. Mech Dev. 1999;83(1-2):39-52.

12. Qu X, Zhai Y, Wei H, Zhang C, Xing G, Yu Y, He F. Characterization and expression of three novel differentiation-related genes belong to the human NDRG gene family. Mol Cell Biochem. 2002;229(1-2):35-44.

13. Zhou RH, Kokame K, Tsukamoto Y, Yutani C, Kato H, Miyata T. Characterization of the human NDRG gene family: a newly identified member, NDRG4, is specifically expressed in brain and heart. Genomics. 2001;73(1):86-97.

14. Yao L, Zhang J, Liu X. NDRG2: a Myc-repressed gene involved in cancer and cell stress. Acta Biochim Biophys Sin (Shanghai). 2008;40(7):625-635.

15. Ellen TP, Ke Q, Zhang P, Costa M. NDRG1, a growth and cancer related gene: regulation of gene expression and function in normal and disease states. Carcinogenesis. 2008;29(1):2-8

16. Yamamura A, Miura K, Karasawa H, Morishita K, Abe K, Mizuguchi Y, Saiki Y, Fukushige S, Kaneko N, Sase T, Nagase H, Sunamura M, Motoi F, et al. Suppressed expression of NDRG2 correlates with poor prognosis in pancreatic cancer. Biochem Biophys Res Commun. 2013; doi:pii: S0006-291X(13)01670-7.

17. Skiriutè D, Vaitkienè $P$, Ašmonienè V, Steponaitis G, Deltuva VP, Tamašauskas A. Promoter methylation of AREG, HOXA11, hMLH1, NDRG2, NPTX2 and Tes genes in glioblastoma. J Neurooncol. 2013; 113(3):441-449.

18. Tepel M, Roerig P, Wolter M, Gutmann DH, Perry A, Reifenberger G, Riemenschneider MJ. Frequent promoter hypermethylation and transcriptional downregulation of the NDRG2 gene at 14q11.2 in primary glioblastoma. Int J Cancer. 2008;123(9):2080-2086.

19. Barreau O, Assié G, Wilmot-Roussel H, Ragazzon B, Baudry C, Perlemoine K, René-Corail F, Bertagna X, Dousset B, Hamzaoui N, Tissier F, de Reynies A, Bertherat J. Identification of a $\mathrm{CpG}$ island methylator phenotype in adrenocortical carcinomas. J Clin Endocrinol Metab. 2013; 98(1):E174-184.

20. Jeschke J, Van Neste L, Glöckner SC, Dhir M, Calmon MF, Deregowski V, Van Criekinge W, Vlassenbroeck I, Koch A, Chan TA, Cope L, Hooker CM, Schuebel KE, et al. Biomarkers for detection and prognosis of breast cancer identified by a functional hypermethylome screen.
Epigenetics. 2012; 7(7):701-709.

21. Liu N, Wang L, Liu X, Yang Q, Zhang J, Zhang W, Wu Y, Shen L, Zhang Y, Yang A, Han H, Zhang J, Yao L. Promoter methylation, mutation, and genomic deletion are involved in the decreased NDRG2 expression levels in several cancer cell lines. Biochem Biophys Res Commun. 2007; 358(1):164-169.

22. Feng L, Xie Y, Zhang H, Wu Y. Down-regulation of NDRG2 gene expression in human colorectal cancer involves promoter methylation and microRNA-650. Biochem Biophys Res Commun. 2011;406(4):534-538.

23. Piepoli A, Cotugno R, Merla G, Gentile A, Augello B, Quitadamo M, Merla A, Panza A, Carella M, Maglietta R, D'Addabbo A, Ancona N, Fusilli S, et al. Promoter methylation correlates with reduced NDRG2 expression in advanced colon tumour. BMC Med Genomics. 2009;2:11. doi: 10.1186/1755-8794-2-11.

24. Furuta H, Kondo Y, Nakahata S, Hamasaki M, Sakoda $\mathrm{S}$, Morishita K. NDRG2 is a candidate tumor-suppressor for oral squamous-cell carcinoma. Biochem Biophys Res Commun. 2010;391(4):1785-1791.

25. Lusis EA, Watson MA, Chicoine MR, Lyman M, Roerig P, Reifenberger G, Gutmann DH, Perry A. Integrative genomic analysis identifies NDRG2 as a candidate tumor suppressor gene frequently inactivated in clinically aggressive meningioma. Cancer Res. 2005;65(16):71217126.

26. Lee DC, Kang YK, Kim WH, Jang YJ, Kim DJ, Park IY, Sohn BH, Sohn HA, Lee HG, Lim JS, Kim JW, Song EY, Kim DM, et al. Functional and clinical evidence for NDRG2 as a candidate suppressor of liver cancer metastasis. Cancer Res. 2008;68(11):4210-4220.

27. Chang X, Li Z, Ma J, Deng P, Zhang S, Zhi Y, Chen J, Dai D. DNA methylation of NDRG2 in gastric cancer and its clinical significance. Dig Dis Sci. 2013; 58(3):715 -723.

28. Qu Y, Dang S, Hou P. Gene methylation in gastric cancer. Clin Chim Acta. 2013; 424:53-65.

29. Peng DF, Razvi M, Chen H, Washington K, Roessner A, Schneider-Stock R, El-Rifai W. DNA hypermethylation regulates the expression of members of the Mu-class glutathione S-transferases and glutathione peroxidases in Barrett's adenocarcinoma. Gut. 2009; 58(1):5-15.

30. Choi SC, Yoon SR, Park YP, Song EY, Kim JW, Kim WH, Yang Y, Lim JS, Lee HG. Expression of NDRG2 is related to tumor progression and survival of gastric cancer patients through Fas-mediated cell death. Exp Mol Med. 2007; 39(6):705-714.

31. Liang ZL, Kang K, Yoon S, Huang SM, Lim JS, Kim JM, Lim JS, Lee HJ. NDRG2 is involved in the oncogenic properties of renal cell carcinoma and its loss is a novel independent poor prognostic factor after nephrectomy. Ann Surg Oncol. 2012; 19(8):2763-2772.

32. Matsusaka K, Funata S, Fukayama M, Kaneda A. DNA methylation in gastric cancer, related to Helicobacter 
pylori and Epstein-Barr virus. World J Gastroenterol. 2014; 20(14):3916-3926.

33. Semper RP, Mejías-Luque R, Groß C, Anderl F, Müller A, Vieth M, Busch DH, Prazeres da Costa C, Ruland J, Groß $\mathrm{O}$, Gerhard M. Helicobacter pylori-Induced IL-1 $\beta$ Secretion in Innate Immune Cells Is Regulated by the NLRP3 Inflammasome and Requires the Cag Pathogenicity Island. J Immunol. 2014; 193(7):3566-3576.

34. Castaño-Rodríguez N, Kaakoush NO, Goh KL, Fock KM, Mitchell HM. The NOD-like receptor signalling pathway in Helicobacter pylori infection and related gastric cancer: a case-control study and gene expression analyses. PLoS One. 2014; 9(6):e98899. doi: 10.1371.

35. Cheng AS, Li MS, Kang W, Cheng VY, Chou JL, Lau SS, Go MY, Lee CC, Ling TK, Ng EK, Yu J, Huang $\mathrm{TH}$, To KF, et al. Helicobacter pylori causes epigenetic dysregulation of FOXD3 to promote gastric carcinogenesis. 2013; 144(1):122-133.

36. Peterson AJ, Menheniott TR, O'Connor L, Walduck AK, Fox JG, Kawakami K, Minamoto T, Ong EK, Wang TC, Judd LM, Giraud AS. Helicobacter pylori infection promotes methylation and silencing of trefoil factor 2 , leading to gastric tumor development in mice and humans. Gastroenterology. 2010; 139(6):2005-2017.

37. Fox JG1, Rogers AB, Whary MT, Ge Z, Ohtani M, Jones EK, Wang TC. Accelerated progression of gastritis to dysplasia in the pyloric antrum of TFF2 -/- C57BL6 $\mathrm{x}$ Sv129 Helicobacter pylori-infected mice. Am J Pathol. 2007; 171(5):1520-1528.

38. Tomita H, Takaishi S, Menheniott TR, Yang X, Shibata W, Jin G, Betz KS, Kawakami K, Minamoto T, Tomasetto C, Rio MC, Lerkowit N, Varro A, et al. Inhibition of gastric carcinogenesis by the hormone gastrin is mediated by suppression of TFF1 epigenetic silencing. Gastroenterology. 2011; 140(3):879-891.

39. Lu XX, Yu JL, Ying LS, Han J, Wang S, Yu QM, Wang XB, Fang XH, Ling ZQ. Stepwise cumulation of RUNX3 methylation mediated by Helicobacter pylori infection contributes to gastric carcinoma progression. Cancer. 2012;118(22): 5507-5517.

40. Roll JD, Rivenbark AG, Jones WD, Coleman WB. DNMT3b overexpression contributes to a hypermethylator phenotype in human breast cancer cell lines. Mol Cancer. 2008; 7:15. doi: 10.1186/1476-4598-7-15.

41. Girault I, Tozlu S, Lidereau R, Bieche I. Expression analysis of DNA methyltransferases 1, 3A, and 3B in sporadic breast carcinomas. Clin Cancer Res. 2003; 9(12):4415-4422.

42. Luczak MW, Jagodzinski PP. The role of DNA methylation in cancer development. Folia Histochem Cytobiol. 2006; 44(3):143-154.

43. Niwa $\mathrm{T}$, Tsukamoto $\mathrm{T}$, Toyoda $\mathrm{T}$, Mori A, Tanaka H, Maekita $T$, Ichinose $M$, Tatematsu $M$, Ushijima $T$. Inflammatory processes triggered by Helicobacter pylori infection cause aberrant DNA methylation in gastric epithelial cells. Cancer Res. 2010; 70(4):1430-40.

44. Jones PA, Baylin SB. The fundamental role of epigenetic events in cancer. Nat Rev Genet. 2002; 3(6):415-28.

45. Bestor TH. The DNA methyltransferases of mammals. Hum Mol Genet. 2000; 9(16):2395-402.

46. Fatemi M1, Hermann A, Gowher H, Jeltsch A. Dnmt3a and Dnmt1 functionally cooperate during de novo methylation of DNA. Eur J Biochem. 2002; 269(20):4981-4.

47. Jair KW, Bachman KE, Suzuki H, Ting AH, Rhee I, Yen RW, Baylin SB, Schuebel KE. De novo CpG island methylation in human cancer cells. Cancer Res. 2006; 66(2):682-92.

48. Su X, Lv C, Qiao F, Qiu X, Huang W, Wu Q, Zhao Z, Fan H. Expression pattern and clinical significance of DNA methyltransferase 3B variants in gastric carcinoma. Oncol Rep. 2010; 23(3):819-26.

49. Hu J, Fan H, Liu D, Zhang S, Zhang F, Xu H. DNMT3B promoter polymorphism and risk of gastric cancer. Dig Dis Sci. 2010; 55(4):1011-6.

50. Yoshida T, Kato J, Maekita T, Yamashita S, Enomoto $\mathrm{S}$, Ando T, Niwa T, Deguchi H, Ueda K, Inoue I, Iguchi M, Tamai H, Ushijima $T$, et al. Altered mucosal DNA methylation in parallel with highly active Helicobacter pylori-related gastritis. Gastric Cancer. 2013;16(4):488-97.

51. Liang X, Zeng J, Wang L, Shen L, Li S, Ma L, Ci X, Yu J, Jia M, Sun Y, Liu Z, Liu S, Li W, et al. participates in the malignant transformation of gastric epithelial cells. Oncotarget. 2014; 5(14):5798-807.

52. Murata M, Thanan R, Ma N, Kawanishi S. Role of nitrative and oxidative DNA damage in inflammation-related carcinogenesis. J Biomed Biotechnol. 2012; 2012: 623019.

53. Kanai Y, Hirohashi S. Alterations of DNA methylation associated with abnormalities of DNA methyltransferases in human cancers during transition from a precancerous to a malignant state. Carcinogenesis. 2007; 28(12):2434-42.

54. Bhardwaj V, Noto JM, Wei J, Andl C, El-Rifai W, Peek RM, Zaika AI. Helicobacter pylori bacteria alter the p53 stress response via ERK-HDM2 pathway. Oncotarget. 2014; [Epub ahead of print].

55. Zaika A, Wei J, Noto J, Peek R Jr. Regulation of the p53 by Helicobacter pylori. Oncotarget. 2012; 3(10):1057-8.

56. Zhou X, Xu G, Yin C, Jin W, Zhang G. Down-regulation of miR-203 induced by Helicobacter pylori infection promotes the proliferation and invasion of gastric cancer by targeting CASK. Oncotarget. 2014; 5(22):11631-40.

57. Ling ZQ, Lv P, Lu XX, Yu JL, Han J, Ying LS, Zhu X, Zhu WY, Fang XH, Wang S, Wu YC. Circulating Methylated XAF1 DNA Indicates Poor Prognosis for Gastric Cancer. PLoS One. 2013;8(6):e67195.

58. Noble JE, Bailey MJ. Quantitation of protein. Meth Enzymol. 2009;463:73-95.

59. Lusis EA, Watson MA, Chicoine MR, Lyman M, Roerig P, Reifenberger G, Gutmann DH, Perry A. Integrative genomic analysis identifies NDRG2 as a candidate tumor 
suppressor gene frequently inactivated in clinically aggressive meningioma. Cancer Res, 2005; 65(16): 71217126.

60. Ling ZQ, Tanaka A, Li P, Nakayama T, Fujiyama Y, Hattori T, Sugihara H. Microsatellite instability with promoter methylation and silencing of hMLH1 can regionally occur during progression of gastric carcinoma. Cancer Lett. 2010; 297 (2):244-251 